\title{
Quercetin induces apoptosis in the methotrexate-resistant osteosarcoma cell line U2-OS/MTX300 via mitochondrial dysfunction and dephosphorylation of Akt
}

\author{
XIANBIAO XIE $^{1}$, JUNQIANG YIN ${ }^{1}$, QIANG JIA ${ }^{2}$, JIN WANG ${ }^{1}$, CHANGYE ZOU ${ }^{1}$, \\ KARI J. BREWER ${ }^{3}$, CHIARA COLOMBO ${ }^{3}$, YAOFEI WANG ${ }^{1}$, GANG HUANG ${ }^{1}$ and JINGNAN SHEN ${ }^{1}$ \\ ${ }^{1}$ Department of Orthopaedic Oncology, First Affiliated Hospital of Sun Yat-Sen University, Guangzhou \\ 510080; ${ }^{2}$ The Institute of Biology, Guizhou Academy of Sciences, Guiyang 550009, P.R. China; \\ ${ }^{3}$ Department of Cancer Biology, MD Anderson Cancer Center, Houston, TX 77054, USA
}

Received March 18, 2011; Accepted April 26, 2011

DOI: $10.3892 /$ or.2011.1328

\begin{abstract}
Quercetin is the most abundant polyphenolic flavonoid found in plants. Several studies suggest that it has potent anticancer effects. The present study examines the apoptosisinducing activity and the underlying mechanism of action of quercetin in a methotrexate (MTX)-resistant osteosarcoma model. Our results showed that quercetin inhibited cell viability in a dose-dependent manner and there was no cross-resistance between MTX and quercetin in U2-OS/MTX300 cells. The induction of apoptosis was observed by flow cytometry and fluorescence staining experiments. Quercetin-induced apoptosis was accompanied by a significant reduction of mitochondrial membrane potential, release of mitochondrial cytochrome $\mathrm{c}$ to the cytosol, activation of caspase-3, down-regulation of Bcl-2, p-Bad and up-regulation of Bax. A remarkable dephosphorylation of Akt was also detected after quercetin treatment. Furthermore, transduction with constitutively active Akt protected against the quercetin-induced dephosphorylation of Akt and Bad as well as poly(ADP-ribose)polymerase (PARP) degradation, while combined treatment with quercetin and LY294002 enhanced the dephosphorylation of Akt, Bad and PARP cleavage in U2-OS/MTX300 cells. Taken together, our results demonstrate that quercetin-induced apoptosis in the MTX-resistant osteosarcoma cells U2-OS/MTX300 was mediated via mitochondrial dysfunction and dephosphorylation of Akt.
\end{abstract}

\section{Introduction}

Osteosarcoma is the most common primary malignant bone tumor diagnosed in children and adolescents (1). Due to the

Correspondence to: Dr Jingnan Shen, Department of Musculoskeletal Oncology, First Affiliated Hospital of Sun Yat-Sen University, Guangzhou 510080, P.R. China

E-mail: shenjn01@hotmail.com

Key words: quercetin, osteosarcoma, apoptosis, methotrexate, mitochondria, Akt development of adjuvant and neo-adjuvant chemotherapy, local control of osteosarcoma and overall survival have improved significantly. Currently used chemotherapy regimens are based on a combination of methotrexate (MTX), doxorubicin, cisplatin and ifosfamide. MTX is the most active one (2). Despite improvements of chemotherapy, a considerable number of osteosarcoma patients develop MTX resistance and die as a result of disease progression (3). Additional therapeutic agents should be evaluated to improve the survival of MTX-resistant osteosarcoma patients.

Quercetin is the most abundant molecule in the extensive class of polyphenolic flavonoids and is found ubiquitously in plants and foods (4). The average daily dietary intake of quercetin is estimated to be $16 \mathrm{mg}$ (5). The bioactivities of quercetin are complex and include antioxidative, antiviral, antibacterial and anti-inflammatory effects $(4,6,7)$. Recently, quercetin was found to possess strong anticancer properties in colon cancer (8-11), breast cancer $(12,13)$, leukemia (14-16), hepatocellular carcinoma (17), pancreatic carcinoma (18), salivary adenoid cystic carcinoma (19) and lung cancer (20). Although the anti-tumor effects of quercetin have been examined in several tumors, very little is known about its effects in osteosarcoma cells. Thus, in this study we used a MTX-resistant model to determine the effects of quercetin on the MTX-resistant osteosarcoma cells, and elucidate the underlying mechanism.

\section{Materials and methods}

Drugs and reagents. Quercetin, MTT (methyl thiazolyl tetrazolium), Hoechst 33258, LY294002, and N-benzyloxycarbonyl-Val-Ala-Asp(O-Me) fluoromethyl ketone (z-VAD-fmk) were purchased from Sigma Chemical Co. (St Louis, MO, USA). Antibodies for cytochrome c, Bax, Bcl-2, phospho-Bad (Ser136), Bad, phospho-AKT (Ser473), Akt and $\beta$-actin were obtained from Cell Signaling (Danvers, MA, USA), while the antibodies for PARP and cleaved PARP were purchased from Abcam (Cambridge, MA, USA).

Cell lines and culture. The MTX-sensitive osteosarcoma cell line U2-OS and the MTX-resistant variant U2-OS/MTX300 
were kindly provided by Dr M. Serra (Istituti Ortopedici Rizzoli, Bologna, Italy). Cells were cultured in Dulbecco's modified Eagle's medium (DMEM) (Gibco, Grand Island, NY, USA), supplemented with $10 \%$ fetal calf serum (Hyclone, Logan, UT, USA), penicillin (10000 U/l) and streptomycin $(100 \mathrm{mg} / \mathrm{l})$ at $37^{\circ} \mathrm{C}$ in a humidified incubator with $5 \% \mathrm{CO}_{2}$. The MTX300-resistant variant was continuously cultured in the medium with $300 \mu \mathrm{g} / 1 \mathrm{MTX}(21)$. The murine amphotropic retroviral packaging cell line, PA317, was obtained from the Cell Bank of Type Culture Collection of the Chinese Academy of Sciences, Shanghai Institute of Cell Biology, Chinese Academy of Sciences and maintained in DMEM medium containing $10 \%$ fetal calf serum and antibiotics.

MTT assay. After quercetin treatment for $48 \mathrm{~h}, 50 \mu \mathrm{l}$ of $1 \mathrm{mg} / \mathrm{ml}$ MTT solution was added to each well of the plate. DMSO $(100 \mu \mathrm{l})$ was added to each well $4 \mathrm{~h}$ later for optical reading at $570 \mathrm{~nm}$. The concentrations required to inhibit cell growth by 50\% $\left(\mathrm{IC}_{50}\right)$ were calculated from the cytotoxicity curves (Bliss's software; Bliss Co., CA, USA).

Clonogenic assay. U2-OS/MTX300 were treated with varying concentrations of quercetin for $24 \mathrm{~h}$. Two hundred viable cells per well were replated, then cultured in regular medium for 10 days and stained with $0.5 \%$ crystal violet solution for $30 \mathrm{~min}$. The staining solution was decanted and the cells were washed with deionized $\mathrm{H}_{2} \mathrm{O}$. Individual colonies were counted.

Fluorescence staining. Cells were collected by centrifugation $(1,500 \mathrm{x} \mathrm{g}, 5 \mathrm{~min})$ following $48 \mathrm{~h}$ quercetin treatment, washed twice with phosphate-buffered saline (PBS), and stained with Hoechst $33258(10 \mathrm{ml}, 10 \mathrm{mg} / \mathrm{l})$ for $10 \mathrm{~min}$ at $37^{\circ} \mathrm{C}$ to visualize nuclei. An Olympus photomicroscope (Olympus, Tokyo, Japan) was used to observe the treatment-induced morphological changes.

Annexin V/PI staining assay. Cells were treated with 0, 10, 25 or $50 \mu \mathrm{M}$ quercetin for $48 \mathrm{~h}$. Next, the cells were collected, washed twice with PBS and resuspended to a concentration of $1 \times 10^{6}$ cells $/ \mathrm{ml}$ and incubated with Annexin V-FITC and propidium iodide for $30 \mathrm{~min}$ in darkness. Cell apoptosis was analyzed by FACScan (Becton-Dickinson, Franklin Lakes, NJ, USA). Data were analyzed by the CellQuest software (Becton-Dickson).

Assay of mitochondrial membrane potential. The mitochondrial membrane potential was measured by using rhodamine 123. After treatment with/without quercetin for $48 \mathrm{~h}$, cells were rinsed with PBS, rhodamine $(10 \mu \mathrm{M})$ was loaded, and then the cells were incubated for $10 \mathrm{~min}$ at $37^{\circ} \mathrm{C}$. Fluorescence intensity of the cells was examined in a Perkin-Elmer L15B fluorescence spectrophotometer (Perkin-Elmer; Waltham, MA, USA) at an excitation and emission wavelength of 480 and $530 \mathrm{~nm}$, respectively. The resultant fluorescence intensity was used as an arbitrary unit representing the mitochondrial transmembrane potential.

Detection of mitochondrial cytochrome c release. After treatment, the cells were harvested and resuspended in ice-cold cell lysis buffer (20 mM HEPES, pH 7.5, $10 \mathrm{mM} \mathrm{KCl}, 1.5 \mathrm{mM}$
$\mathrm{MgCl}_{2}, 1 \mathrm{mM}$ EDTA, $1 \mathrm{mM}$ EGTA, $1 \mathrm{mM}$ DTT, $250 \mathrm{mM}$ sucrose, protease inhibitor mixture) and incubated for $1 \mathrm{~h}$ at $4^{\circ} \mathrm{C}$. The lysates were then homogenized. Homogenates were centrifuged at $12,000 \mathrm{x}$ g for $5 \mathrm{~min}$ at $4^{\circ} \mathrm{C}$. Supernatants were collected and further centrifuged at 100,000 $\mathrm{x}$ g for $30 \mathrm{~min}$ at $4^{\circ} \mathrm{C}$ to obtain the cytosolic fraction, which was then analyzed for cytochrome $\mathrm{c}$ by Western blotting.

Assay of caspase-3 activity. The caspase- 3 activity was measured by using a caspase- 3 colorimetric assay kit (caspase colorimetric assay kits; BioVision, Inc.) as directed by the manufacturer. The optical density was measured at $405 \mathrm{~nm}$ by a spectrophotometer.

Western blot analysis. Cells were lysed with a protein extraction reagent (Pierce Biotechnology, Rockford, IL, USA). For each sample, $30 \mu \mathrm{g}$ of protein were run on an SDS-PAGE gel and transferred onto polyvinylidene difluoride membranes. Next, the membranes were incubated with primary antibodies for $12 \mathrm{~h}$ at $4^{\circ} \mathrm{C}$ followed by 3 washes in Tris-buffered saline with Tween-20 (TBST) for 5 min each. Secondary antibody conjugated with horseradish peroxidase was added to the membrane and incubated for $1 \mathrm{~h}$ at room temperature. Protein bands were visualized on X-ray film using an enhanced chemiluminescence detection system.

Transduction. The pLNCX and pLNCX-Myr-Akt retroviral plasmids were purchased from Addgene (Cambridge, MA, USA). PA317 was transfected with pLNCX and pLNCX-MyrAkt by DOSPER reagents (Roche Molecular Biochemicals, Indianapolis, IN) following the manufacturer's instructions. Next, the supernatants were collected $48 \mathrm{~h}$ after transfection. U2-OS/MTX300 cells were then incubated with individual retroviral supernatant for $6 \mathrm{~h}$ in the presence of $2 \mu \mathrm{g} / \mathrm{ml}$ polybrene (Sigma Chemical Co.) on two successive days. Cells were then incubated at $37^{\circ} \mathrm{C}$ in a $\mathrm{CO}_{2}$ incubator for $24 \mathrm{~h}$ prior to quercetin treatment.

Statistical analysis. All data were derived from at least 3 independent experiments and the results are expressed as the mean \pm SD. Differences were assessed using the Student's t-test or one-way ANOVA. P $<0.05$ was deemed statistically significant. All analyses were performed by SPSS 13.0 (SPSS Inc., Chicago, IL, USA).

\section{Results}

Effects of quercetin on the viability of U2-OS/MTX300 cells. Quercetin demonstrated a potent cytotoxic effect in both the MTX-sensitive U2-OS cells and the MTX-resistant U2-OS/ MTX300 cells in a dose-dependent manner (Fig. 1A). The $\mathrm{IC}_{50}$ values of quercetin for the U2-OS and the U2-OS/MTX300 cells were $24 \pm 5$ and $22 \pm 4 \mu \mathrm{M}$, respectively; these differences were not statistically significant $(P>0.05)$. Similarly, quercetin significantly and dose-depndently decreased U2-OS/MTX300 colony formation compared with untreated controls $(\mathrm{P}<0.05$; Fig. $1 \mathrm{~B}$ and $\mathrm{C}$ ). These initial results indicate that quercetin inhibits the viability of MTX-resistant osteosarcoma cells in vitro and there is no cross-resistance between MTX and quercetin in U2-OS/MTX300 cells. 
A

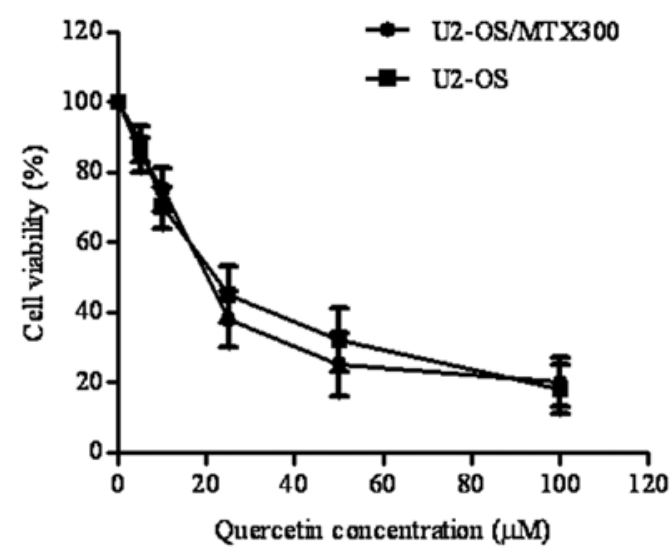

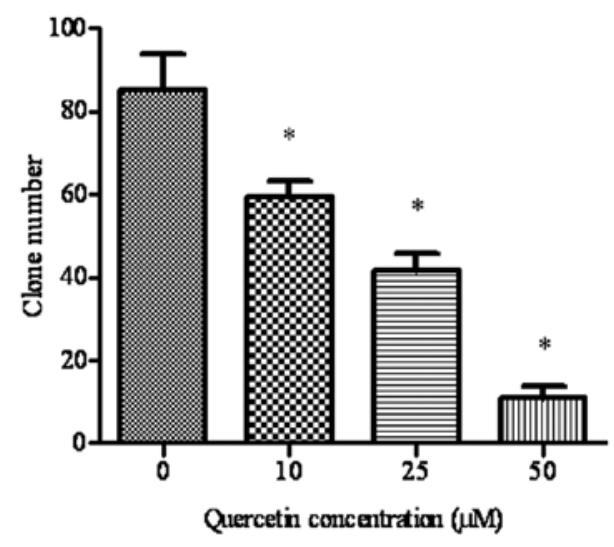

B

Quercetin concentration $(\mu \mathrm{M})$

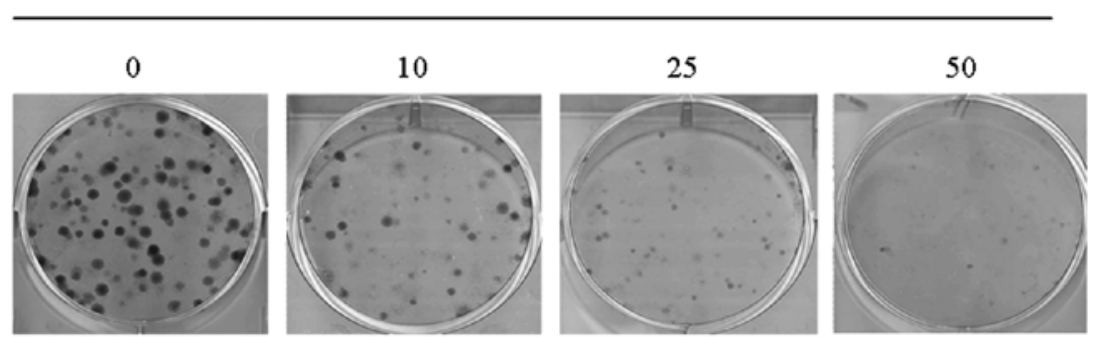

Figure 1. Cytotoxicity of quercetin in U2-OS/MTX300 cells. (A) U2-OS and U2-OS/MTX300 cells were incubated with $0,5,10,25,50$ or $100 \mu \mathrm{M}$ of quercetin for $48 \mathrm{~h}$. The cell survival rate was determined by the MTT assay. The cytotoxicity is expressed as the percentage of cell survival rate compared with the control. The data are expressed as the mean \pm SD. (B) U2-OS/MTX300 cells were pretreated with $0,10,25$ or $50 \mu \mathrm{M}$ of quercetin for $24 \mathrm{~h}$, and the effect of quercetin on the colony formation was detected. (C) The number of clones are expressed as the mean $\pm \mathrm{SD}$. ${ }^{*} \mathrm{P}<0.05$ vs. control.

0

A

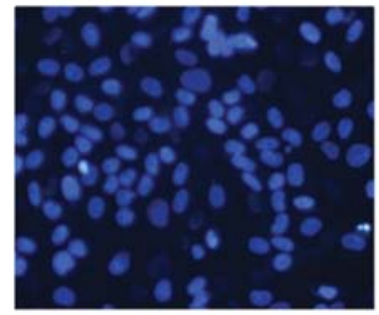

25

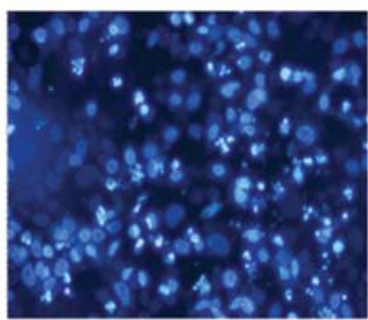

50
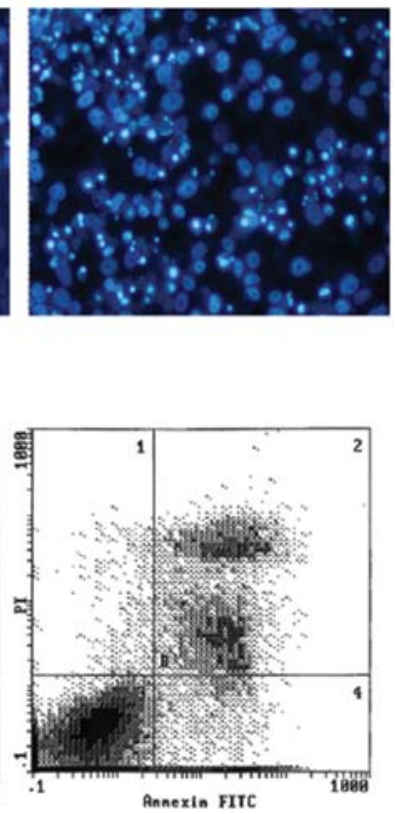

Annexin FITC

Figure 2. Apoptosis-inducing effects of quercetin in U2-OS/MTX300 cells. (A) Cells were incubated with $0,10,25$ or $50 \mu \mathrm{M}$ quercetin for $48 \mathrm{~h}$ and then Hoechst staining was performed to detect the morphology change. Each picture was taken at a magnification of x100. (B) Annexin V/PI staining assay were used to detect the apoptosis rate.
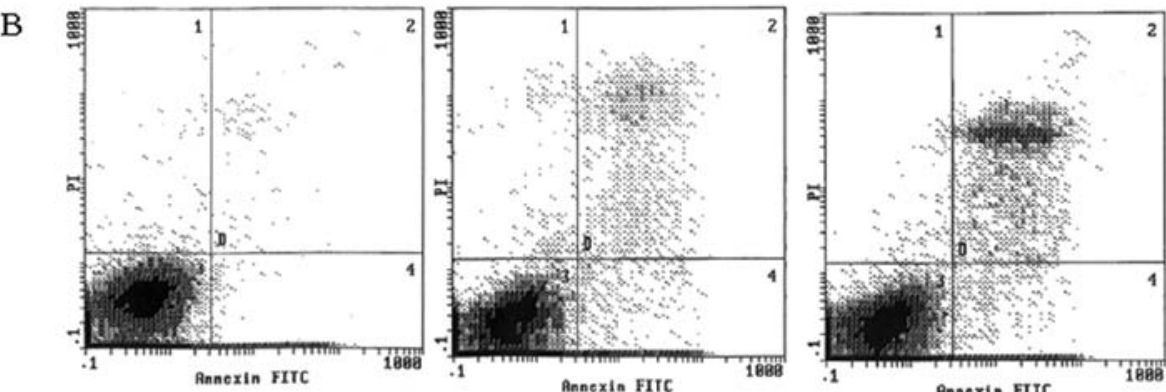

Annexin FITC 
A

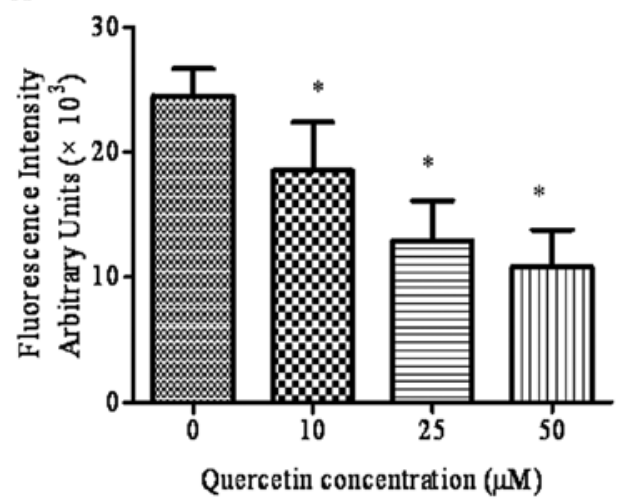

B

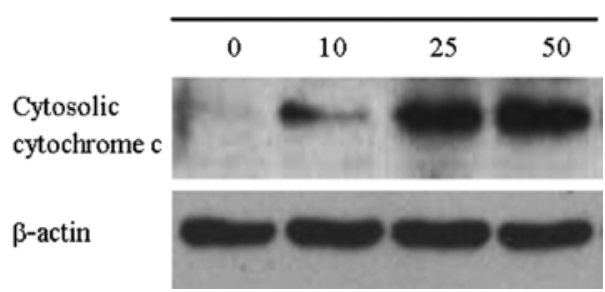

Figure 3. Measurement of mitochondrial membrane potential and cytoplasmic cytochrome c release in U2-OS/MTX300 cells during quercetin treatment. (A) U2-OS/MTX300 cells were incubated without or with quercetin for $48 \mathrm{~h}$. The mitochondrial membrane potential was measured. The data are expressed as mean $\pm \mathrm{SD}$ of 3 determinations, ${ }^{*} \mathrm{P}<0.05$ vs. the control group. (B) Cytoplasmic cytochrome c release was detected by Western blotting.
Quercetin induced apoptosis of U2-OS/MTX300 cells. Fluorescence staining and flow cytometry analysis were used to examine whether quercetin could induce apoptosis in U2-OS/MTX300 cells. As shown in Fig. 2A, quercetintreated cells presented with several hallmark characteristics of apoptosis, such as chromatin condensation, nuclear fragmentation and the appearance of apoptotic bodies after quercetin treatment. The apoptosis rates in cells treated with 0,10 , 25 or $50 \mu \mathrm{M}$ quercetin for $48 \mathrm{~h}$ were $3 \pm 2 \%, 13 \pm 4 \%, 22 \pm 2 \%$ and $34 \pm 5 \%$, respectively (Fig. 2B). The P-value was $<0.05$ between the control group and all quercetin treatment groups. Collectively, these results suggest that quercetin suppresses cell viability by inducing apoptosis.

Changes of mitochondrial membrane potential and release of cytochrome c from mitochondria. To ascertain the role of the mitochondria in quercetin-induced apoptosis in U2-OS/ MTX300 cells, the mitochondrial membrane potential as well as cytochrome c levels in the cytosol were examined. Quercetin decreased the mitochondrial membrane potential in a dosedependent manner (Fig. 3A). Concomitantly, cytochrome c translocation to the cytosol was confirmed by Western blotting (Fig. 3B). These data strongly support the hypothesis that mitochondria dysfunction is involved in quercetin-induced apoptosis in U2-OS/MTX300 cells.

Caspase- 3 was activated after quercetin treatment. Caspase-3 is a central molecule in the apoptotic cascade due to its ability to

B
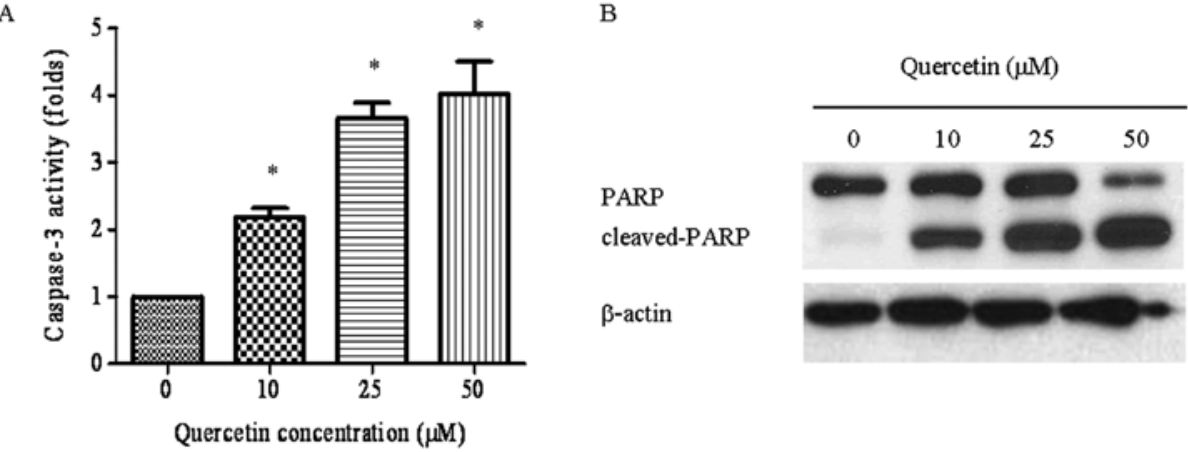

D

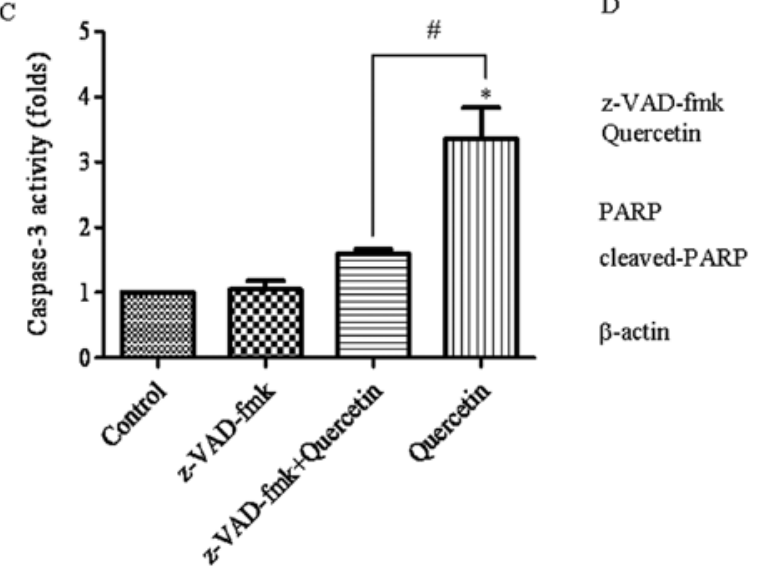

Figure 4. Activation of caspase-3 in U2-OS/MTX300 cells by quercetin. (A) After quercetin treatment, caspase-3 activity was detected by a colorimetric assay. ${ }^{*} \mathrm{P}<0.05$ vs control (B) The level of PARP and cleaved-PARP were detected by Western blotting. (C) Effect of $\mathrm{z}$-VAD-fmk on the quercetin-induced caspase-3 activation. U2-OS/MTX300 cells were pretreated with/without z-VAD-fmk $(25 \mu \mathrm{M})$ for $2 \mathrm{~h}$ and then incubated with quercetin $(25 \mu \mathrm{M})$ for $48 \mathrm{~h}$. All values are the mean \pm SD of 3 determinations, ${ }^{*} \mathrm{P}<0.05$ vs. the control and ${ }^{\#} \mathrm{P}<0.05$ vs. the quercetin-treated cells. (D) Effect of $\mathrm{z}$-VAD-fmk on the quercetin-induced PARP cleavage. 
A

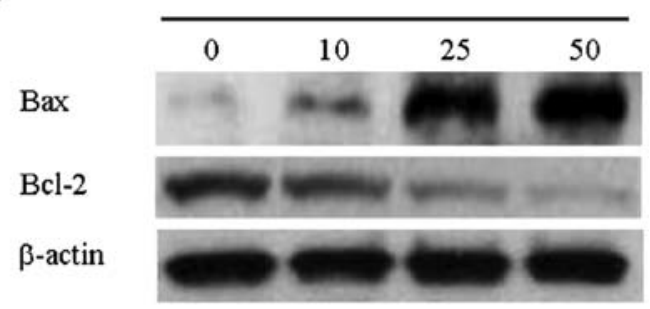

B

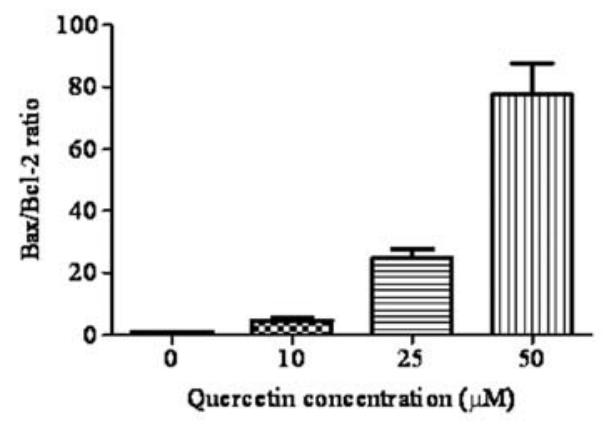

C

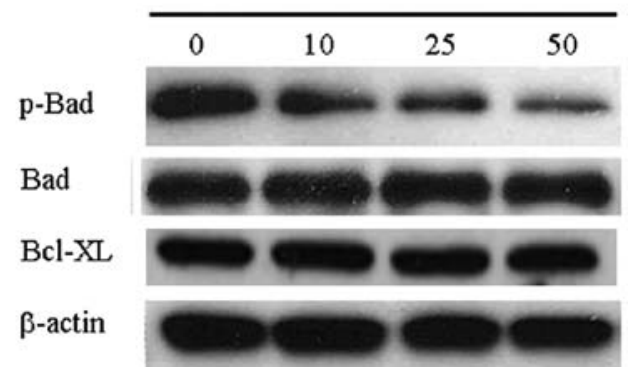

Figure 5. Expression of Bcl-2 family proteins in quercetin-treated U2-OS MTX300 cells. (A)U2-OS/MTX300 cells were treated with/without quercetin for $48 \mathrm{~h}$. After treatment, the levels of Bcl-2 and Bax were analyzed by Western blot analysis. (B) The ratio of the Bax and Bcl-2 protein expression was shown as mean \pm SD from 3 independent experiments. ${ }^{*} \mathrm{P}<0.05$ vs. the control. (C) Western blot analyses for p-Bad, Bad and Bcl-xL after quercetin treatment.

cleave PARP and other critical cellular proteins. In the present study, quercetin treatment activated caspase-3 (Fig. 4A). Meanwhile, the level of cleaved-PARP was also highly increased (Fig. 4B). However, this activation was inhibited by pretreatment with the caspase inhibitor, z-VAD-fmk (Fig. 4C and D). These data indicate that activation of caspase-3 likely played a critical role in quercetin-induced apoptosis in U2-OS/ MTX300.

Effects of quercetin on the Bcl family proteins. To better understand the underlying molecular forces promoting the quercetin-induced apoptosis in U2-OS/MTX300 cells, protein expression of $\mathrm{Bax}, \mathrm{Bcl}-2$, pBad, $\mathrm{Bad}$ and $\mathrm{Bcl}-\mathrm{xL}$ were examined by Western blotting. Following a 48-h treatment with quercetin at doses of $0,10,25$ or $50 \mu \mathrm{M}$, we observed a significant decrease in Bcl-2 accompanied by an inverselycorrelated and dose-dependent increase in the protein levels of Bax (Fig. 5A), and an increase in the Bax/Bcl-2 ratio (Fig. 5B). Although there were no observable changes of total Bad and $\mathrm{Bcl}-\mathrm{xL}$ levels, the down-regulation of $\mathrm{p}$-Bad was detected
(Fig. 5C). These results suggest that quercetin could induce apoptosis in U2-OS/MTX300 cells by affecting the Bcl family proteins.

Dephosphorylation of Akt was involved in quercetin-induced apoptosis in U2-OS/MTX300 cells. Bad is a downstream target of Akt and the phosphorylation of Bad is important to the integrity of the mitochondrial membrane system. Therefore, the phosphorylation of Akt was analyzed. As predicted, a dose-dependent dephosphorylation of Akt was observed after quercetin treatment (Fig. 6A). To further confirm the involvement of Akt in the quercetin-induced apoptosis, the U2-OS/ MTX300 cells were treated with/without quercetin following the transduction of constitutively active Akt (pLNCX-MyrAkt) and empty vector (pLNCX). The constitutively active Akt protected against quercetin-induced dephosphorylation of Akt, Bad and PARP cleavage (Fig. 6B). On the other hand, LY294002 (a PI3K inhibitor) used to inhibit the activity of Akt and quercetin were combined together to treat U2-OS/ MTX300 cells. We found that LY294002 could significantly enhance the quercetin-induced dephosphorylation of Akt, Bad and the degradation of PARP (Fig. 6C). These results suggested that dephosphorylation of Akt was involved in the quercetin-induced apoptosis.

\section{Discussion}

Despite continuing efforts to improve chemotherapeutic response in osteosarcoma, the development of drug resistance remains a challenge. In fact, only $50-60 \%$ of tumors are chemosensitive (3), indicating the dismal outcome that occurs far too often in this disease. One potential strategy to overcome known chemoresistance in osteosarcoma is to seek out alternative anti-cancer agents, particularly those emerging from natural medicine (22).

Quercetin is an all-natural chemical found in many types of plants and food which shows promising anti-cancer activity in several studies, including a phase I clinical trial (23). In vitro studies confirm that quercetin at a range of $10-100 \mu \mathrm{M}$ inhibits cell viability, likely through cell cycle arrest, and induces apoptosis (8-20). While quercetin has been evaluated in several tumors, very little is known about its effects in MTX-resistant osteosarcoma. In this study, we provide evidence that quercetin acts as a potent anti-cancer drug, reduces cellular viability and initiates apoptosis in MTX-resistant osteosarcoma. There was no cross-resistance between MTX and quercetin in U2-OS/ MTX300 cells. The $48 \mathrm{~h} \mathrm{IC}_{50}$ of quercetin treatment in our model was $22 \pm 4 \mu \mathrm{M}$ and apoptosis was confirmed by Hoechst staining and flow cytometric analysis. These results are consistent with previous studies.

Although the exact mechanism of quercetin-induced apoptosis is still unclear, possible explanations include: downregulation of the epidermal growth factor receptor (EGFR) family $(8,9)$, promotion of TRAIL-induced apoptosis (10), activation of the AMPK signaling pathway (11), up-regulation of Bax and post-translational regulation of Bcl-2 (14), activation of the intrinsic apoptosis pathway $(15,17,20)$, down-regulation of Mcl-1 and activation of Bax (16), suppression of the PI3K/ $\mathrm{Akt} / \mathrm{IKK}_{\alpha} / \mathrm{NF}-\mathrm{KB}$ pathway (19) and induction of histone acetylation (24). Given the vast effects of quercetin in various cell 
A

\begin{tabular}{|c|c|c|c|c|}
\hline \multirow[b]{2}{*}{ p-Akt } & 0 & 10 & 25 & 50 \\
\hline & & $=$ & $=0$ & $\Leftrightarrow$ \\
\hline Akt & & & & \\
\hline$\beta$-actin & & & & \\
\hline
\end{tabular}

B

B
p-Akt
Akt
p-Bad
Bad
PARP
cleaved-PARP
$\beta$-actin

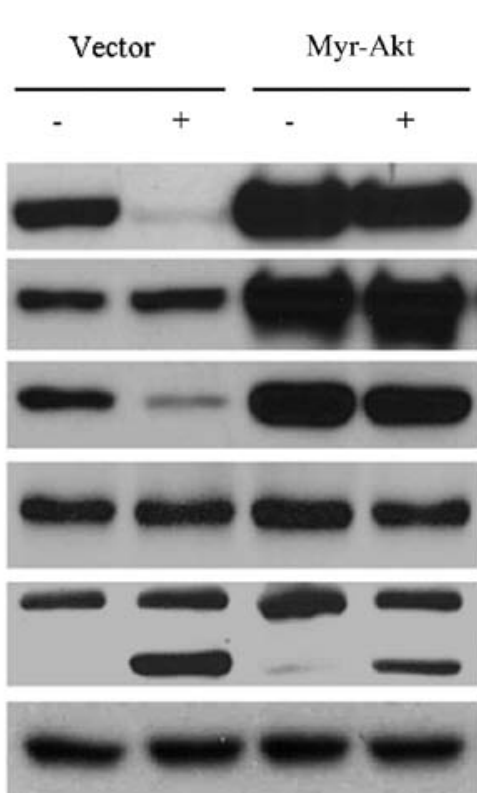

$\mathrm{C}$

Quercetin

p-Akt

Akt

p-Bad

Bad

PARP

cleaved-PARP

$\beta$-actin

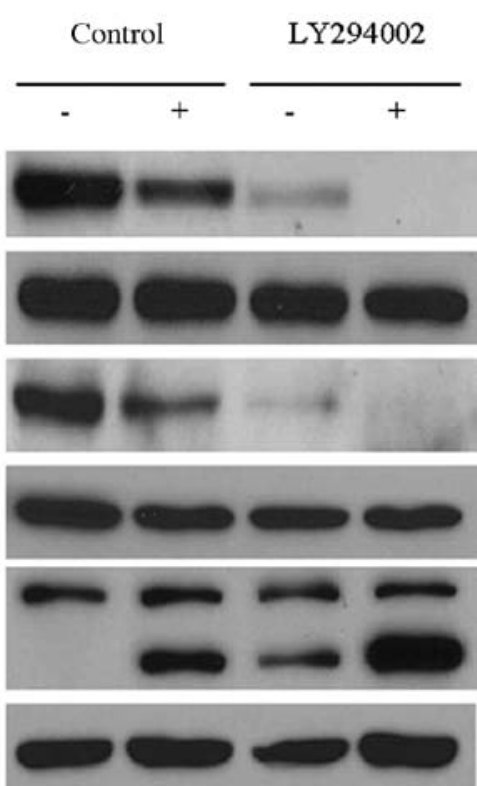

Figure 6. Dephosphorylation of Akt was involved in quercetin-induced apoptosis. (A) U2-OS/MTX300 cells were treated with quercetin for 48 h. After the treatment, cell lysates were extracted, and the levels of p-Akt and Akt were analyzed by Western blot analysis. Quercetin treatment induced obviously dephosphorylation of Akt. (B) Constitutively active Myr-Akt and control vector-transducted U2-OS/MTX300 cells were treated with/without quercetin and the p-Akt, Akt, p-Bad, Bad, PARP and cleaved-PARP were detected by Western blotting. (C) Western blot analyses for p-Akt, Akt, p-Bad, Bad, PARP and cleaved-PARP in U2-OS/MTX300 cells treated with quercetin $(25 \mu \mathrm{M})$ and LY294002 $(5 \mu \mathrm{M})$.

types, its exact molecular mechanism for inducing apoptosis may be cell-type specific.

Mitochondria have been reported to play a critical role in the intrinsic mechanisms of apoptosis (25). The loss of mitochondrial membrane potential facilitates the opening of the outer membrane pore and results in cytochrome c translocation from the mitochondria to cytosol (26). In the present study, progressive deterioration of the mitochondrial membrane potential and subsequent release of cytochrome c into the cytosol was observed after quercetin treatment. In addition, many studies have suggested that caspase- 3 can be activated through mitochondria-dependent signaling proteins by the release cytochrome $\mathrm{c}$ into the cytoplasm (27). Caspase-3 is classified as an executioner caspase due to its ability to cleave numerous critical cellular proteins including PARP, and generally once activation of caspase- 3 has occurred, the cell is committed to death via apoptosis. Our data showed that caspase-3 was highly activated after quercetin treatment. Indeed, pre-incubation with z-VAD-fmk, a caspase inhibitor, effectively decreased the caspase- 3 activation. Results of the present study reinforce the idea that quercetin-induced apop- tosis in U2-OS/MTX300 cells occurs through mitochondria dependent caspase activation.

Previous research has shown that mitochondrial-mediated apoptosis is facilitated by the Bcl-2 homology family proteins (25). This family includes pro-apoptotic proteins, such as Bax and Bad, as well as anti-apoptotic proteins like Bcl-2 and $\mathrm{Bcl}-\mathrm{xL}$. The ratio of pro- and anti-apoptotic proteins such as $\mathrm{Bax} / \mathrm{Bcl}-2$ is thought to determine, at least in part, the susceptibility of cells to a death signal (27). In the present study, quercetin-induced apoptosis in U2-OS/MTX300 cells was accompanied by down-regulation of $\mathrm{Bcl}-2$ and up-regulation of Bax, resulting in a significant increase of $\mathrm{Bax} / \mathrm{Bcl}-2$ ratio. No observable changes in Bad and Bcl-xL were detected, however, significant down-regulation of p-Bad was observed. Previous studies have shown that the apoptotic stimuli can dephosphorylate Bad and release it from the 14-3-3 protein $(28,29)$. Consequently, Bad will compete with Bcl-2/Bcl-xL in binding to $\operatorname{Bax}(28,29)$. Therefore, Bax is released and facilitates cytochrome $\mathrm{c}$ translocation to trigger the cell death sequence (30). Taken together, our results suggest that the quercetin-induced apoptosis in U2-OS/MTX300 is regulated 
by a balance between the pro- and anti-apoptotic Bcl-2 family proteins within the cells.

To further understand the mechanism of quercetin-induced apoptosis in U2-OS/MTX300 cells, the role of Akt, a central regulatory protein of cell survival, in this process was investigated. Many experiments have shown that functional Akt could phosphorylate Bad at Ser136 to promote the stabilization of the mitochondrial membrane system and cell survival (30). In our study, Akt was obviously dephosphorylated after quercetin treatment. Insertion of constitutively active Akt could attenuate the dephosphorylation of Akt, Bad and the degradation of PARP induced by quercetin. Moreover, combination of quercetin and LY294002 remarkably enhanced the quercetin-induced dephosphorylation of Akt, Bad and the cleavage of PARP. These data strongly suggest that quercetin-induced apoptosis was closely associated with dephosphorylation of Akt.

In conclusion, the present study provides evidence that quercetin is a potent anti-cancer agent in MTX-resistant osteosarcoma cells U2-OS/MTX300. Quercetin-induced apoptosis in U2-OS/MTX300 occurred through the mitochondrialdependent pathway and dephosphorylation of Akt. These data indicate that quercetin may have merit as a potential chemotherapeutic agent for MTX-resistant osteosarcoma.

\section{Acknowledgements}

This study was supported by the National Natural Science Foundation of China (nos.: 30200285 and 30500616); the Natural Science Foundation of Guangdong Province (nos.: 05300822, 4009423 and 23E0161/2005); the Science and Technology Planning of Guangdong Province, China (no. 2007B031405008) and the Ministry of Science and Technology of Guizhou Province, China [G(2009)4013 and NY(2009)3021].

\section{References}

1. Ferguson WS and Goorin AM: Current treatment of osteosarcoma. Cancer Invest 19: 292-315, 2001.

2. Delepine N, Delepine G, Bacci G, et al: Influence of methotrexate dose intensity on outcome of patients with high grade osteogenic osteosarcoma. Analysis of the literature. Cancer 78: 2127-2135, 1996.

3. Lewis IJ, Nooij MA, Whelan J, et al: Improvement in histologic response but not survival in osteosarcoma patients treated with intensified chemotherapy: a randomized phase III trial of the European Osteosarcoma Intergroup. J Natl Cancer Inst 99: 112-128, 2007.

4. Harborne JB and Williams CA: Advances in flavonoid research since 1992. Phytochemistry 55: 481-504, 2000.

5. Hertog MG, Hollman PC, Katan MB, et al: Intake of potentially anticarcinogenic flavonoids and their determinants in adults in The Netherlands. Nutr Cancer 20: 21-29, 1993.

6. Kyaw M, Yoshizumi M, Tsuchiya K, et al: Atheroprotective effects of antioxidants through inhibition of mitogen-activated protein kinases. Acta Pharmacol Sin 25: 977-985, 2004.

7. Di Carlo G, Mascolo N, Izzo AA, et al: Flavonoids: old and new aspects of a class of natural therapeutic drugs. Life Sci 65: 337-353, 1999.

8. Richter M, Ebermann R and Marian B: Quercetin-induced apoptosis in colorectal tumor cells: possible role of EGF receptor signaling. Nutr Cancer 34: 88-99, 1999.
9. Kim WK, Bang MH, Kim ES, et al: Quercetin decreases the expression of ErbB2 and ErbB3 proteins in HT-29 human colon cancer cells. J Nutr Biochem 16: 155-162, 2005

10. Psahoulia FH, Drosopoulos KG, Doubravska L, et al: Quercetin enhances TRAIL-mediated apoptosis in colon cancer cells by inducing the accumulation of death receptors in lipid rafts. Mol Cancer Ther 6: 2591-2599, 2007.

11. Kim HJ, Kim SK, Kim BS, et al: Apoptotic effect of quercetin on HT-29 colon cancer cells via the AMPK signaling pathway. J Agric Food Chem 58: 8643-8650, 2010.

12. Choi JA, Kim JY, Lee JY, et al: Induction of cell cycle arrest and apoptosis in human breast cancer cells by quercetin. Int J Oncol 19: 837-844, 2001.

13. Dechsupa S, Kothan S, Vergote J, et al: Quercetin, Siamois 1 and Siamois 2 induce apoptosis in human breast cancer MDA-mB435 cells xenograft in vivo. Cancer Biol Ther 6: 56-61, 2007.

14. Duraj J, Zazrivcova K, Bodo J, et al: Flavonoid quercetin, but not apigenin or luteolin, induced apoptosis in human myeloid leukemia cells and their resistant variants. Neoplasma 52: 273-279, 2005.

15. Wang IK, Lin-Shiau SY and Lin JK: Induction of apoptosis by apigenin and related flavonoids through cytochrome c release and activation of caspase- 9 and caspase- 3 in leukaemia HL-60 cells. Eur J Cancer 35: 1517-1525, 1999.

16. Cheng S, Gao N, Zhang Z, et al: Quercetin induces tumorselective apoptosis through down-regulation of Mcl-1 and activation of Bax. Clin Cancer Res 16: 5679-5691, 2010.

17. Granado-Serrano AB, Martin MA, Bravo L, et al: Quercetin induces apoptosis via caspase activation, regulation of $\mathrm{Bcl}-2$, and inhibition of PI-3-kinase/Akt and ERK pathways in a human hepatoma cell line (HepG2). J Nutr 136: 2715-2721, 2006.

18. Mouria M, Gukovskaya AS, Jung Y, et al: Food-derived polyphenols inhibit pancreatic cancer growth through mitochondrial cytochrome $\mathrm{C}$ release and apoptosis. Int J Cancer 98: 761-769, 2002.

19. Sun ZJ, Chen G, Hu X, et al: Activation of PI3K/Akt/IKK-alpha/ NF-kappaB signaling pathway is required for the apoptosis-evasion in human salivary adenoid cystic carcinoma: its inhibition by quercetin. Apoptosis 15: 850-863, 2010.

20. Kuhar M, Sen S and Singh N: Role of mitochondria in quercetinenhanced chemotherapeutic response in human non-small cell lung carcinoma H-520 cells. Anticancer Res 26: 1297-1303, 2006.

21. Serra M, Scotlandi K, Manara MC, et al: Establishment and characterization of multidrug-resistant human osteosarcoma cell lines. Anticancer Res 13: 323-329, 1993.

22. Kong JM, Goh NK, Chia LS, et al: Recent advances in traditional plant drugs and orchids. Acta Pharmacol Sin 24: 7-21, 2003.

23. Mulholland PJ, Ferry DR, Anderson D, et al: Pre-clinical and clinical study of QC12, a water-soluble, pro-drug of quercetin. Ann Oncol 12: 245-248, 2001.

24. Lee WJ, Chen YR and Tseng TH: Quercetin induces FasL-related apoptosis, in part, through promotion of histone $\mathrm{H} 3$ acetylation in human leukemia HL-60 cells. Oncol Rep 25: 583-591, 2011.

25. Brunelle JK and Letai A: Control of mitochondrial apoptosis by the Bcl-2 family. J Cell Sci 122: 437-441, 2009.

26. Kantrow SP and Piantadosi CA: Release of cytochrome $\mathrm{c}$ from liver mitochondria during permeability transition. Biochem Biophys Res Commun 232: 669-671, 1997.

27. Budihardjo I, Oliver H, Lutter M, et al: Biochemical pathways of caspase activation during apoptosis. Annu Rev Cell Dev Biol 15: 269-290, 1999.

28. Yang $\mathrm{E}$, Zha J, Jockel J, et al: Bad, a heterodimeric partner for Bcl-XL and Bcl-2, displaces Bax and promotes cell death. Cell 80: 285-291, 1995

29. Zha J, Harada H, Yang E, et al: Serine phosphorylation of death agonist BAD in response to survival factor results in binding to 14-3-3 not BCL-X(L). Cell 87: 619-628, 1996.

30. Datta SR, Dudek H, Tao X, et al: Akt phosphorylation of BAD couples survival signals to the cell-intrinsic death machinery. Cell 91: 231-241, 1997. 